\title{
ELECTROCARDIOGRAPHIC CHANGES ASSOCIATED WITH ALLERGIC URTICARIA
}

\author{
BY \\ A. S. ROGEN AND E. RICHARDSON \\ From Stobhill General Hospital and Ruchill Hospital, Glasgow
}

Received March 27, 1961

One of us (Rogen, 1957) has reported a patient in whom extensive cardiographic abnormalities were associated with massive urticaria, the abnormalities being of short duration and clearing with rapid recovery from the urticaria. Her condition is summarized shortly as Case 2. The first patient reported here as Case 1 had associated mild urticaria only, but the electrocardiogram showed features similar to those previously reported by others. We have been given notes about another patient (Case 3), similar except that the cardiographic changes lasted for longer.

Case 1. A young man, aged twenty-one, had been ill since he had eaten a sandwich made with tinned pilchards. Six hours after eating the sandwich he developed severe generalized abdominal pain, which lasted until the following morning: there was occasional vomiting and diarrhœa in the form of two to three loose, normally coloured, stools in the day for the five days until he was admitted to hospital. Shortly after the onset of the abdominal pain he felt "a gripping pain" in the left mammary region radiating down the inner aspect of both arms to the elbows, the pain lasting about ten minutes at a time and recurring roughly every three hours. This type of pain was troublesome for the first three days of his illness, but for the two days before his admission it alternated with two attacks of severe bilateral constricting chest pain lasting up to 13 hours. With the second attack of severe long-lasting pain he felt dizzy and weak and sweated. It was shortly after the cessation of this attack of pain that he was admitted to Ruchill Hospital. He gave no history of recent cold, sore throat, or joint pains.

He was a well-built young man who indulged in boxing and swimming without chest pain or other ill effects. There was no history of recent injections or of drug taking and no history of any skin rash following the taking of medicines in the past. One sister, aged 17, had psoriasis but there was no history of allergic disease in the patient, his parents, or his two sisters. The patient had no diarrhœa or chest pain while in hospital. He was not dehydrated. He had a mild urticarial eruption on the back of his chest which cleared within three days. There was no triple rhythm or other significant abnormality on clinical examination of the heart. His blood pressure was labile and was most commonly around $120 / 70 \mathrm{~mm}$. $\mathrm{Hg}$. Two specimens of stool were negative for intestinal pathogenic organisms. Hæmoglobin, white blood count, and differential white blood count were within normal limits, and no abnormality was found in the urine or on radiological examination of heart or lungs.

A cardiogram taken on admission showed changes compatible with antero-lateral ischæmic heart damage (Fig. 1): that taken three days later was normal (Fig. 2). No drug treatment was given.

The only evidence of an allergic reaction in this patient was the fine urticarial eruption noted on his back; this cleared rapidly after his admission to hospital and was absent when the second cardiogram was taken. The possibility of the whole illness being due to allergy might be supported by the fact that the illness dated from the eating of tinned fish, an eating habit in which he had never indulged before and insisted he would never repeat.

He had been a patient in Stobhill General Hospital just over a year previously with a similar type of illness. On that occasion he was admitted with a history of having had severe anterior chest pain for about three hours, maximal retrosternally and of a constricting quality. It was considered to have the characteristics of ischæmic cardiac pain. An electrocardiogram taken a few hours after pain had ceased showed 

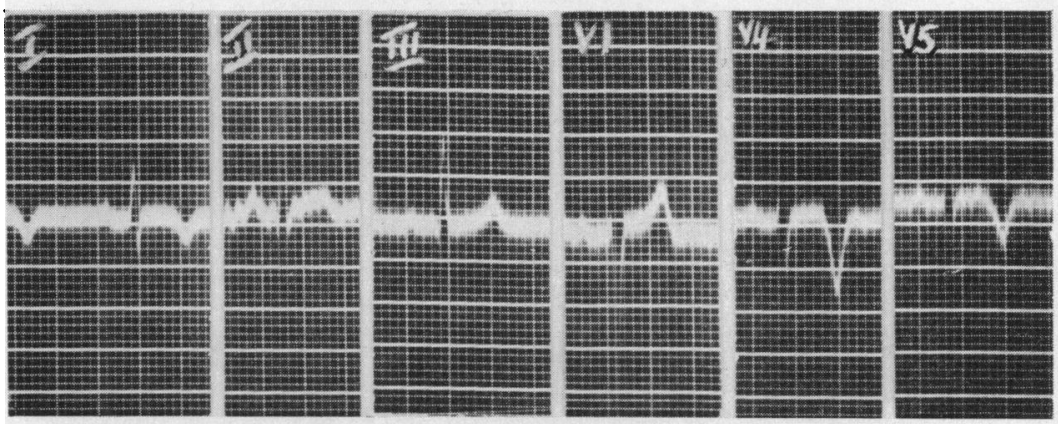

Fig. 1.-Electrocardiogram showing antero-lateral ischæmic heart damage.

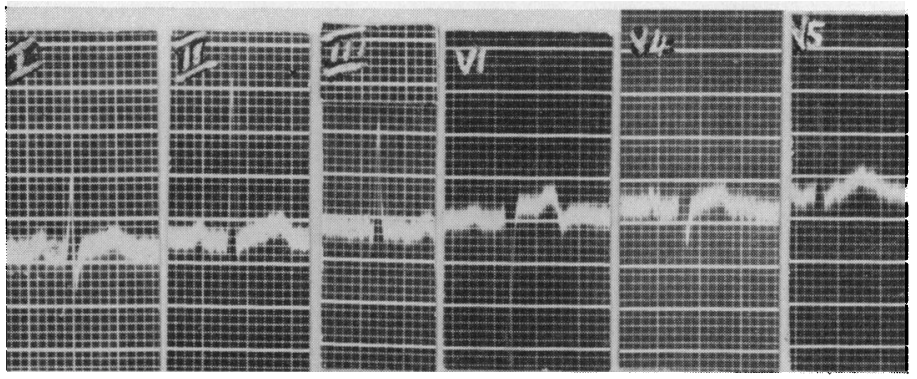

FIG. 2.-Electrocardiogram showing return to a normal pattern three days later. Case 1.
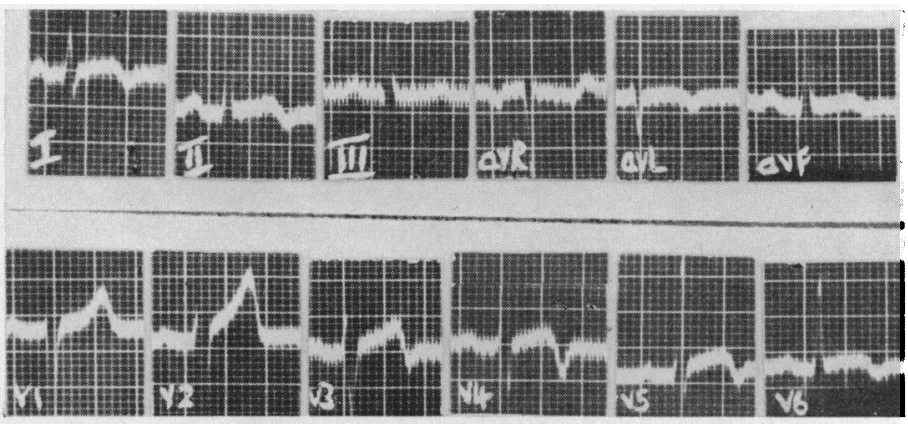

Fig. 3.-Electrocardiogram of the same man a year earlier, showing anterolateral ischæmic heart damage, ? infarction. Case 1.

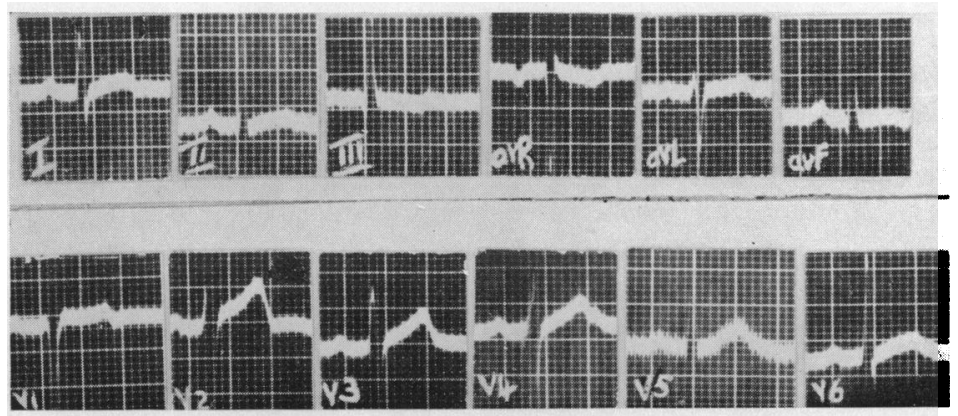

Fig. 4.-Electrocardiogram showing return to a normal pattern 48 hours later. Case 1. 
changes compatible with recent antero-lateral myocardial infarction (Fig. 3). Forty-eight hours later these changes had disappeared and the tracing was normal (Fig. 4).

On this occasion the complaint of chest pain was part of an acute illness which included sore throat, stiffness in the elbows, vomiting, and the development of an ill-defined urticarial rash on the back and chest. This rash disappeared in about twenty-four hours. The illness was considered by the attending physicians at that time to be in the nature of an allergic response to an unknown factor. Virus pericarditis was considered but negative results were obtained from serum studies to influenza types $\mathrm{A}, \mathrm{B}$, and $\mathrm{C}$, to the adenovirus group, psittacosis, and $\mathbf{Q}$ fever.

Case 2. A young woman, aged 23 years, had had bronchitis and a sore throat for one month before admission to hospital; for a few days before she had had vague abdominal pains and slight pains, not troublesome and apparently without constitutional upset, in the elbow and shoulder joints. She was sent to hospital as suffering from rheumatic fever. Two days after admission she developed an extensive urticarial rash affecting the forehead, eyelids, lips, shoulders, arms, hips, and knees. Her eyes were almost closed, the lips were grossly swollen, and she had difficulty in breathing. The cardiogram done at this stage showed extensive $\mathrm{S}-\mathrm{T}$ and $\mathrm{T}$ wave changes, not typical of infarction or pericarditis; there was $\mathrm{S}-\mathrm{T}$ depression and $\mathrm{T}$ wave inversion in leads II and III and the chest leads. The urticaria cleared rapidly after the administration of adrenalin and a cardiogram taken three days after the first showed a normal pattern. The cause of the urticaria remained in doubt although acetylsalicylic acid, taken in the form of a proprietary preparation up till the time of her admission, and sodium salicylate given in the hospital for the two days preceding the urticaria were thought of as possible causative factors.

Dr. Maurice Campbell has written to us as follows. "I wonder if you would like to include the notes of a somewhat similar case that I saw several times between 1955 and 1959. I thought that his signs of cardiac infarction might have been due to the effects of urticaria on his heart muscle, because of the close association and the unusually good recovery. I put aside his notes to wait for the chance of seeing a similar case and in 1957 I saw an older man who developed severe urticaria in hospital and this too was followed by severe cardiac infarction. But in this case the patient died and there was very severe coronary atheroma and the classical picture of coronary obstruction and cardiac infarction without any unusual features, so I have not yet had the opportunity of using my notes of the first patient." $\mathrm{He}$ is included as Case 3.

Case 3. A young man had been flying in the R.A.F. since October, 1938, when he was 20 . From 194045 he served in heavy bombers and flew in 77 incidents, being intercepted by fighters on six or seven occasions and involved in several crash landings. From 1945-55 he served in Transport Command, flying over much of the world and spending a good deal of time in the Far East. He had always had good health until he had urticaria in September, 1952, followed by severe attacks of giant urticaria in November and again in December, 1953. He was under almost constant treatment for this, including a course of autohæmotherapy, from then until June, 1954. By this time, he was married with three children.

On June 17th and again on the 19th, when he was 36 and had been flying almost continuously for 16 years, he had his first attacks of anginal pain. On June 21st within twenty-four hours of developing another attack of generalized urticaria he had more severe pain and was admitted to the R.A.F. Hospital at Halton with a diagnosis of coronary thrombosis. There was depression of the S-T segment in leads III, V2, V3, and V4 with a small $Q$ wave and perhaps slight S-T elevation in lead I. A week later these changes were more obvious. Two months later, there was still a small $Q$ wave in lead $I$ and $T I$ had become inverted. He was in hospital for three months and was discharged from the R.A.F. By the middle of October, four months after the onset of his attack, all these changes were disappearing.

In April and October, 1955, when he was first seen by M.C., he was getting on very well and by October he was working as a commercial traveller and leading a normal life without any anginal pain. There was nothing abnormal to find on examination except that the aorta was a little prominent and unfolded: the blood pressure was $125 / 85 \mathrm{~mm}$. Hg. The $\mathrm{T}$ wave was still almost flat and there was a minute $\mathrm{Q}$ wave in lead I: in leads V1 to V4 there was a fairly large and notched QS wave. In May 1956 the T wave was small and upright in lead $\mathrm{I}$.

He was given a disability pension for urticaria aggravated by service but not for coronary thrombosis. On appeal, however, his pension was increased and both causes were accepted as aggravated by service. He has continued to get on well. He has taken over a shop in the West country and works very hard throughout the summer. He has had no urticaria since 1957, when it was not severe, and no angina at any 
time, even on strenuous exertion, since 1954. The $T$ wave in lead I had become more upright in 1958 and T in V6 upright instead of flat in October 1959, but there were still large QS waves in V1 to V4.

Comment. In younger patients with cardiac infarction there is more reason to look for some special cause such as abnormalities in fat metabolism or a family history. Nothing unusual could be found about the dietetic habits of this patient. He neither avoided fat nor ate an unusual amount of it, though he was fairly liberal with butter. His blood cholesterol in 1955 was $177 \mathrm{mg}$. per $100 \mathrm{ml}$. It is true that his father had died recently at the age of 65 with pneumonia and cardiac infarction, but there was no other known family history and his mother was well and all his four grandparents had lived till the eigth or ninth decades and were not known to have died from coronary heart disease. The patient's coronary symptoms seemed to be closely associated with his giant urticaria and M.C. therefore wrote to his doctor "He could be an exceptional case where he had giant urticaria of the heart muscle producing the changes like coronary thrombosis. I do not know of such a case being proved. His outlook is good in any case, but would be even better if this were true."

\section{Discussion}

Electrocardiographic changes indicative of myocardial infarction and ischæmia have been reported during serum sickness (Roussak, 1954), and it is accepted that certain drugs may also cause changes in the cardiogram suggestive of myocardial ischæmia with or without associated symptoms. Foster and Layman (1952) have reported cardiographic findings suggesting myocardial infarction associated with urticaria presumed to be due to hypersensitivity to cincophen. Three cases of hypersensitivity to acetyl salicylic acid expressed by "an angina pectoris syndrome," in two cases accompanied by urticaria, were reported by Shookhoff and Lieberman (1933); cardiographic changes were reversed within two minutes of the giving of adrenalin. A patient was reported by Werley (1932) who, in an attack of angina pectoris with angioneurotic œdema and migraine, had isoelectric $T$ waves in lead II, the $T$ waves becoming upright and of normal height one week later when symptoms had subsided.

An allergic basis may well explain the symptoms and findings of our Case 1. This is suggested in the light of the two comparable illnesses that occurred acutely and settled rapidly and completely, on both occasions associated with an urticarial rash and on the second following on a possible allergen in the form of tinned fish. Coronary artery involvement in the allergic process, whether in the form of spasm or swelling could provide the electrocardiographic changes pictured here.

It is of interest to us that so little reference has been made to the association between urticaria and cardiographic changes. The fact that one of us has seen two cases in the past four years, one of the patients having had two episodes, would suggest that it is not a rare condition. On the other hand Maurice Campbell, with his wide experience and on the alert since 1955, when he first suspected this association, has not seen a second one. His patient (Case 3) is like our Case 2 in that both had giant urticaria and the onset of symptoms was related to this event. The fact that our case cleared so quickly prompted the suggestion that there was localized involvement of a coronary artery by the urticarial process (? swelling, ? spasm). Possibly, Campbell's suggestion that his case had giant urticaria of the heart muscle may explain the changes being of longer duration and one might postulate that the urticaria of the heart muscle, if extreme and not clearing rapidly, might produce local damage of a sufficient degree to leave residual ill effects.

\section{SUMMARY}

We have reported the case of a young man, who, in the space of eighteen months, has suffered two illnesses characterized by severe gripping central chest pain, associated each time with urticaria and the second time following the eating of tinned fish. On both occasions the electrocardiogram showed changes indicative of ischæmic heart damage: it returned to normal on the first occasion some time within forty-eight hours and on the second some time within three days. An allergic 
basis to the electrocardiographic changes is suggested. We have compared them with two other cases.

Cases 1 and 2 had many similar features but in the latter the urticaria was massive. In both the cardiographic changes cleared rapidly and completely. Case 3 differs in that although the cardiographic changes were apparently related in time to the onset of massive urticaria, they have been slower to clear. In the abscence of any clear picture of what is causing the cardiographic abnormalities, it may be that the apparent differences in recovery rates are not incompatible with the suggestion made separately by Campbell and ourselves that the urticaria was the factor responsible for the changes, our ideas varying as to the exact method of how the urticaria affected the heart and thereby produced the effects seen in the electrocardiogram.

We are very grateful to Dr. Maurice Campbell for sending us the details of his case.

We should like to express our thanks to Professor Stanley Alstead and Dr. Wm. Fulton for access to the records while the patient was under their care in Stobhill General Hospital, to Dr. J. Lawson, Physician Superintendent of Ruchill Hospital, for permission to report the case and to Mr. P. Waldie, Medical Photographer, Stobhill General Hospital, for the electrocardiograms.

\section{REFERENCES}

Foster, R. F., and Layman, J. D. (1952). J. Amer. med. Ass., 148, 203.

Rogen, A. S. (1957). Scot. med. J., 2, 407.

Roussak, N. J. (1954). Brit. Heart J., 16, 218.

Shookhoff, C., and Lieberman, D. L. (1933). J. Allergy, 4, 506.

Werley, G. (1932). Med. J. Rec., 136, 417. 